\title{
Review Article \\ Community Based HIV Prevention Intervention in Developing Countries: A Systematic Review
}

\author{
Sarah Ibrahim ${ }^{1}$ and Souraya Sidani ${ }^{2}$ \\ ${ }^{1}$ School of Nursing, McMaster University, 1280 Main Street West, Hamilton, ON, Canada L8S 4K1 \\ ${ }^{2}$ Daphne Cockwell School of Nursing, Ryerson University, Toronto, ON, Canada M5B 2K3 \\ Correspondence should be addressed to Sarah Ibrahim; sarah.ibrahim@ryerson.ca
}

Received 7 May 2014; Revised 29 July 2014; Accepted 22 August 2014; Published 23 September 2014

Academic Editor: Julee B. Waldrop

Copyright (c) 2014 S. Ibrahim and S. Sidani. This is an open access article distributed under the Creative Commons Attribution License, which permits unrestricted use, distribution, and reproduction in any medium, provided the original work is properly cited.

\begin{abstract}
Aim. To describe the features and examine effects of community based HIV prevention interventions implemented in developing countries on HIV-related knowledge and self-reported risk behavior. Background. The HIV epidemic has a significant impact on developing countries, increasing the prevalence of HIV among young persons. Community-based HIV prevention interventions have been designed to improve HIV-related knowledge and decrease engagement in risk behavior. Variations in the design and implementation of these interventions have been reported, which may influence their effectiveness. Design. Systematic review. Method. Data were extracted on the characteristics of the study and interventions and effects of the interventions on knowledge and self-report of risk behavior. Results. In total, 10 studies were included in the review. Overall, the results showed variability in theoretical underpinning, dose, and mode of delivery of the interventions. Multicomponent interventions that used mixed teaching methods produced beneficial effects on knowledge and self-reported risk behavior. Conclusion. Examining the characteristics of HIV-prevention interventions provides direction for researchers in developing efficient interventions to improve knowledge and reduce engagement in self-reported risk behavior and, in turn, decrease transmission of HIV.
\end{abstract}

\section{Introduction}

The HIV/AIDS epidemic has had a significant impact on morbidity and mortality rates, with estimates of 33.4 million persons living with HIV [1] and 25 million lives claimed worldwide [2]. It is reported that more than $95 \%$ of persons living with HIV reside in developing countries. In Asia and the Pacific, there are over 7 million persons living with HIV [3]. The continent of Africa has been the most affected by the epidemic with prevalence rates ranging between $2 \%$ and 5.2\% in West and Central Africa [4]; in Sub-Saharan Africa the total number of persons living with HIV is estimated to be two thirds of the global total number of infected persons [4].

Young persons between 15 and 24 years of age are most affected by the epidemic, with estimates of 6,000 and 7,000 becoming infected each day [4]; 95\% of these reside in developing countries [5]. Young men constitute one-quarter of persons living with HIV and are at risk of contracting HIV because of their engagement in risk behaviors (e.g., unprotected sexual intercourse and multiple sexual partners)
[6]. Young women also are at an increased risk of contracting HIV because of sociocultural factors such as lack of power and formal education, oppression, poverty, and lower socioeconomic status. These factors contribute to young women's inability to be assertive to negotiate safer sexual practices and loss of control with sexual interactions $[7,8]$. In addition, both young women and men tend to lack sexual health education and often receive inaccurate and unreliable information; therefore, they do not have the knowledge and skills to engage in healthy behaviors, which put them at risk of contracting HIV [6].

There is no cure for AIDS to date; hence the emphasis is on the prevention of HIV through educational and behavioral interventions. These interventions inform young persons of strategies to prevent the contraction of HIV and provide support to engage in health behaviors, respectively [9-11]. Community based HIV prevention interventions are commonly offered to young persons. This approach to providing interventions is suitable to young persons who spend a large proportion of their time in the community [12]. However, 
community based HIV prevention interventions have not been consistently designed as there are reported variations in the theoretical underpinning, components, dose, mode of delivery, and teaching method of the interventions. Such variations in the characteristics and in the implementation of interventions may influence (1) the validity of conclusions about their effectiveness, (2) the fidelity of their implementation, and, in turn, (3) the achievement of hypothesized outcomes [13]. Furthermore, the variations make it difficult to identify the features of the intervention (e.g., components and mode of delivery) that are most effective in producing favourable outcomes. Yet, such knowledge is critical for designing and delivering community based HIV prevention interventions that are most efficient and effective in enhancing HIV-related knowledge and reducing engagement in sexual risk behavior, with the ultimate goal of decreasing the spread of HIV among young persons living in developing countries.

This systematic review examined the characteristics of community based interventions and the influence of these characteristics on outcomes.

The objectives were as follows.

(1) To describe the characteristics of community based HIV prevention interventions as implemented in developing countries.

(2) To determine the influence of intervention characteristics on improving knowledge and decreasing selfreported engagement in sexual risk behavior among young persons residing in developing countries.

\section{Methods}

2.1. Selection Criteria. Studies were included in this descriptive systematic review if they (1) targeted young persons between 15 and 24 years of age; (2) evaluated community based HIV prevention interventions implemented in developing countries; (3) assessed the effects of the interventions on HIV-related knowledge and or self-reported engagement in sexual behaviors that put the young persons at risk for HIV; and (4) the study report was in English.

2.2. Search Strategies. A literature search was conducted to identify studies of community based HIV prevention interventions. The electronic databases used to locate relevant studies were Cumulative Index to Nursing and Allied Health Literature (CINAHL), Educational Research Information Clearinghouse (ERIC), Medline/PUBMED (National Library of Medicine), EBSCO, and Social Science Citation Index. The search was completed with the following key words in combination: HIV interventions, HIV prevention, community, education, knowledge, risk behavior, condom use, young persons, and developing countries. A supplemental search was also conducted by examining the reference lists from the retrieved studies to ensure comprehensiveness of the search.

2.3. Data Extraction. Data from articles that met the inclusion criteria were extracted relating to characteristics of the study and of the community based HIV prevention interventions. The conceptual and operational definitions of the characteristics were derived from work of Sidani and Braden [13] and Fan and Sidani [1]. A coding scheme was developed to retrieve and code the data.

The information related to the study characteristics covered (1) first author's last name and year of publication; (2) study setting (e.g., specific country); (3) environment in which the intervention was delivered (e.g., church, community clinic, and community center); and (4) characteristics of the sample including age (mean and range), gender (percentage of women and men), and level of education (mean years of education).

The characteristics of the interventions were theoretical underpinning, type and number of components, dose, mode of delivery, and teaching method.

Theoretical underpinning refers to the theory underlying the design of the intervention. It was operationalized into (1) use of theory (coded as $0=$ not used, $1=$ used) and (2) the specific theory used (e.g., Theory of Planned Behavior). An intervention component is defined as a "set of interrelated activities aimed at addressing a common goal" [13, page 110]. The types of components comprising HIV prevention interventions included (1) educational, which consisted of relaying HIVrelated information such as methods of HIV transmission and prevention; (2) behavioral, which involved strategies targeting change in sexual risk behavior; and (3) combined, which integrated educational and behavioral components. In addition, the number of components was counted. Dose is the level at which the intervention was delivered [13] and is usually described in terms of amount (length of each session in minutes), frequency (number of sessions given over a specified time period), and duration (total time period over which sessions were delivered). Mode of Delivery refers to the technique utilized to provide the intervention to participants. It is operationalized in terms of strategy and format. Strategy is the method used to convey information; it includes brochures, pamphlets, media, communication through face-to-face interactions, or a combination of these strategies. Format indicates the medium for providing the intervention sessions such as one-on-one, group, or a mix of individual and group. Mode of delivery was operationalized as follows: strategy (coded as written material, media, faceto-face, and mixed) and format (coded as one-on-one, group, and mixed). Teaching Method used to provide the community based HIV prevention intervention which entails (1) didactic, which involves limited interaction and discussions between the participants and interventionist (e.g., written material or formal presentations); (2) interactive, which involves active engagement of participants throughout the learning process (e.g., hands-on-practice and group discussion); (3) mixed, which encompasses both didactic and interactive teaching methods. Teaching method was coded as didactic, interactive, or mixed.

2.4. Outcomes. Community based HIV prevention interventions are proposed to reduce the transmission of HIV and 
in turn, to the containment of the HIV epidemic through their effects on the following outcomes: increasing HIVrelated knowledge specific to the transmission, risk factors, and prevention; in turn, knowledge supports engagement in healthy sexual behavior and reduces performance of risk behaviors among young persons $[14,15]$. This review was concerned with the effects of the interventions on knowledge and self-reported risk behaviour. Knowledge was operationalized as young person's ability to (1) define HIV; (2) identify HIV transmission methods; and (3) identify preventative approaches and behaviors to reduce risk of contracting HIV [16]. Self-reported risk behavior was operationally defined as not using condoms during sexual intercourse with one or more sexual partners [12, 17-19]. Data on the outcomes included (1) the instruments used to measure the outcomes of interest, (2) the reliability and validity of outcomes measures, and (3) whether or not improvement in the outcomes was found after implementation of the intervention.

2.5. Data Analysis. The data pertaining to the characteristics of the study and the HIV-prevention interventions were analyzed descriptively. Data on the influence of intervention characteristics on its effectiveness in improving HIV-related knowledge and decreasing self-reported sexual risk behavior were synthesized using the vote-counting procedure. According to this procedure, the studies were divided into three categories: studies with significant results in the hypothesized direction, studies with significant results in the direction opposite to hypothesized one, and nonsignificant results.

\section{Results}

3.1. Literature Search. The literature search resulted in 15 citations. Of these, three reported the pretest and posttest outcomes for the same intervention. Two were duplicates addressing the same intervention; therefore, one (which provided the most comprehensive report on the intervention evaluation) was selected for inclusion in the review. Of the remaining, two reported on pretest and two reported on posttest measures for two interventions. The remaining articles reported on the evaluation of six different interventions and were selected for this systematic review. A total of ten publications were included in the review.

3.2. Study Characteristics. The studies were published between 1998 and 2010 and were conducted in Tanzania $(n=2)$, Zimbabwe $(n=1)$, South Africa $(n=3)$, Kenya $(n=1)$, Zambia $(n=1)$, Sri Lanka $(n=1)$, and Cameroon $(n=1)$. Six studies used a quasi-experimental design [12, 18-22]; three studies used an experimental design [17, 23, 24]; and one used a nonexperimental design involving ethnography and survey [25].

The location for the delivery of HIV-prevention intervention was identified in six of the studies. The locations included community clinics [17-19], community centres [18, 19], inschool $[12,17-20,24]$, out of school $[12,17,19]$, churches [20], and sport clubs [20].
3.3. Participant Characteristics. Sample sizes varied from 89 [25] to 9,219 [17] participants with the mean age ranging between 13.5 and 20.5 years. The interventions were delivered to young males and young females. Eight studies [12, 17, 1924] reported data on participants' level of education; the number of years of formal education ranged from 0 to 9 .

\subsection{Intervention Characteristics}

3.4.1. Theoretical Underpinning. Five of the ten studies did not report using a theory to guide the development of the intervention $[17,18,20,22,24]$ and five studies did. The theories used were the Achievement Goal Theory and elements of the Social Cognitive Theory [12], the Social Learning Theory and Stages of Change Model [19], Theory of Behavior Change [21], Social Construction Theory [25], and Participatory Learning Approaches [23].

3.4.2. Component. All studies reported using two components, educational and behavioral, as shown in Table 1 .

3.4.3. Dose. Five studies reported on the length of the sessions delivered (amount), ranging from 40 [17] to 180 minutes $[23,29]$. Five studies reported on the frequency of providing the sessions, which was described as 1 session per week [23], 2-12 sessions per year [17], 3 sessions per week [25], 6 sessions per week to 22 sessions per year [29], and 13 sessions over 6-8 weeks [23]. The duration of the intervention was reported in seven studies $[12,17,19,20,22,23,25]$, ranging from 4 to 208 weeks (4 years).

3.4.4. Mode of Delivery. A mix of strategies was used to deliver the intervention as mentioned in six studies: a combination of written material [18, 21, 22, 24, 25]; media outlets $[17,18,21,22]$; and face-to-face format $[17,18,24,25]$. The mode for delivering the intervention was face-to-face in four studies $[12,19,20,23]$, group format in five studies [12, 20, 2325], and mixed (one-on-one and group interaction) in four studies $[17-19,22]$.

3.4.5. Teaching Method. A mixed teaching method was described in nine studies (Table 1). The educational component included the relay of HIV-related information through formal lectures in seven studies $[12,17,19,20,22,23,25]$ and print materials in four studies [18, 21, 22, 24]. Different teaching methods were applied in the behavioral components including video $[17,21]$, television and radio [18, 21], music and songs [24], drama [17, 19, 20, 23, 24], story-telling [17, 19], role-playing $[17,19,20,23-25]$, games $[17,18]$, recreational activities such as soccer $[12,17,18]$, and body-mapping [19].

3.5. Intervention Effectiveness. The outcomes were measured with reliable and valid instruments. For instance, knowledge was measured with the HIV-Knowledge Questionnaire (HIV-K-Q) and attitude to condom use scale. Instruments assessing self-reported engagement in risk behaviours included the Health International Behavioral Surveys and the Decision Making Scale. Other scales such as the World 


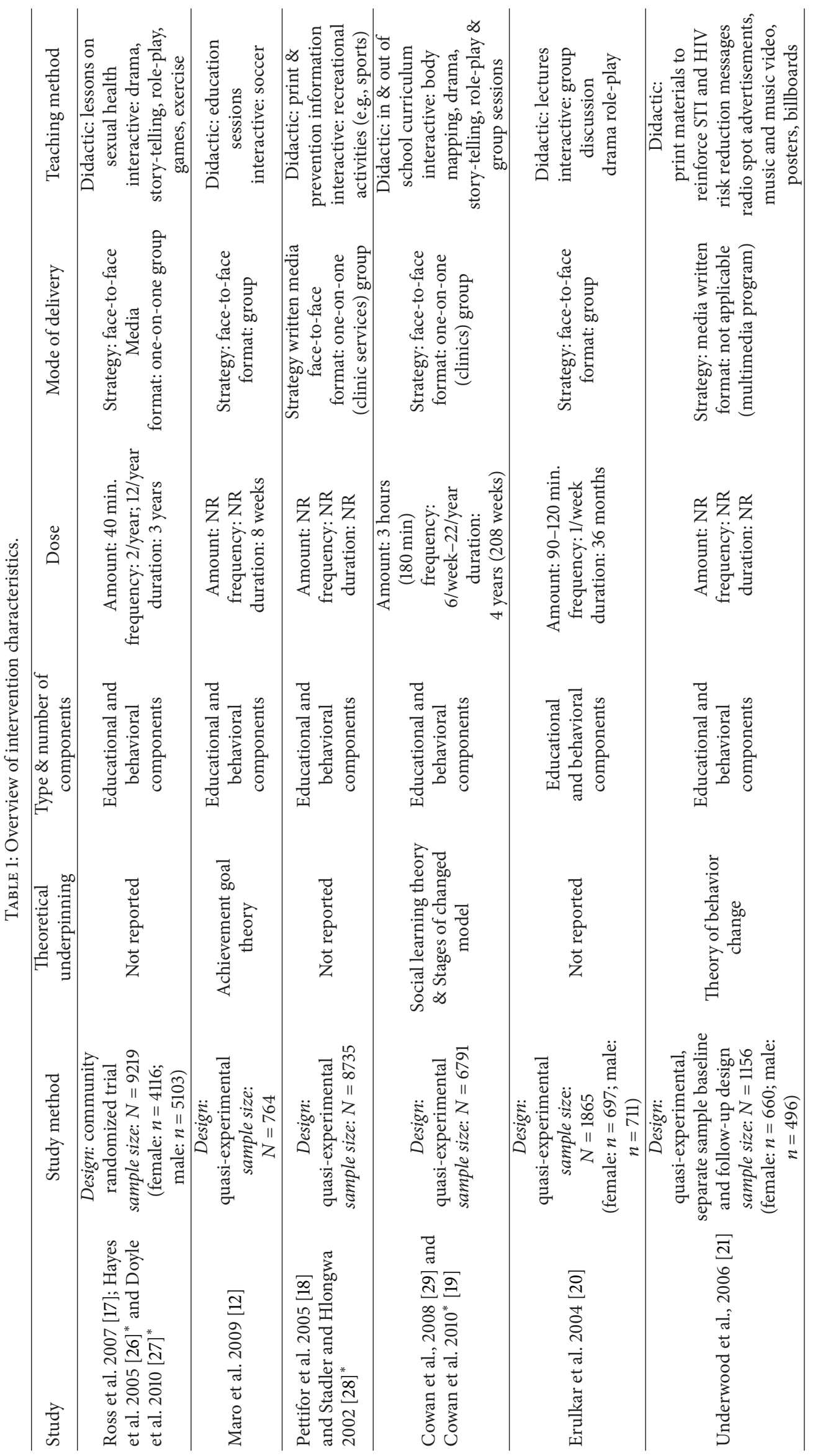




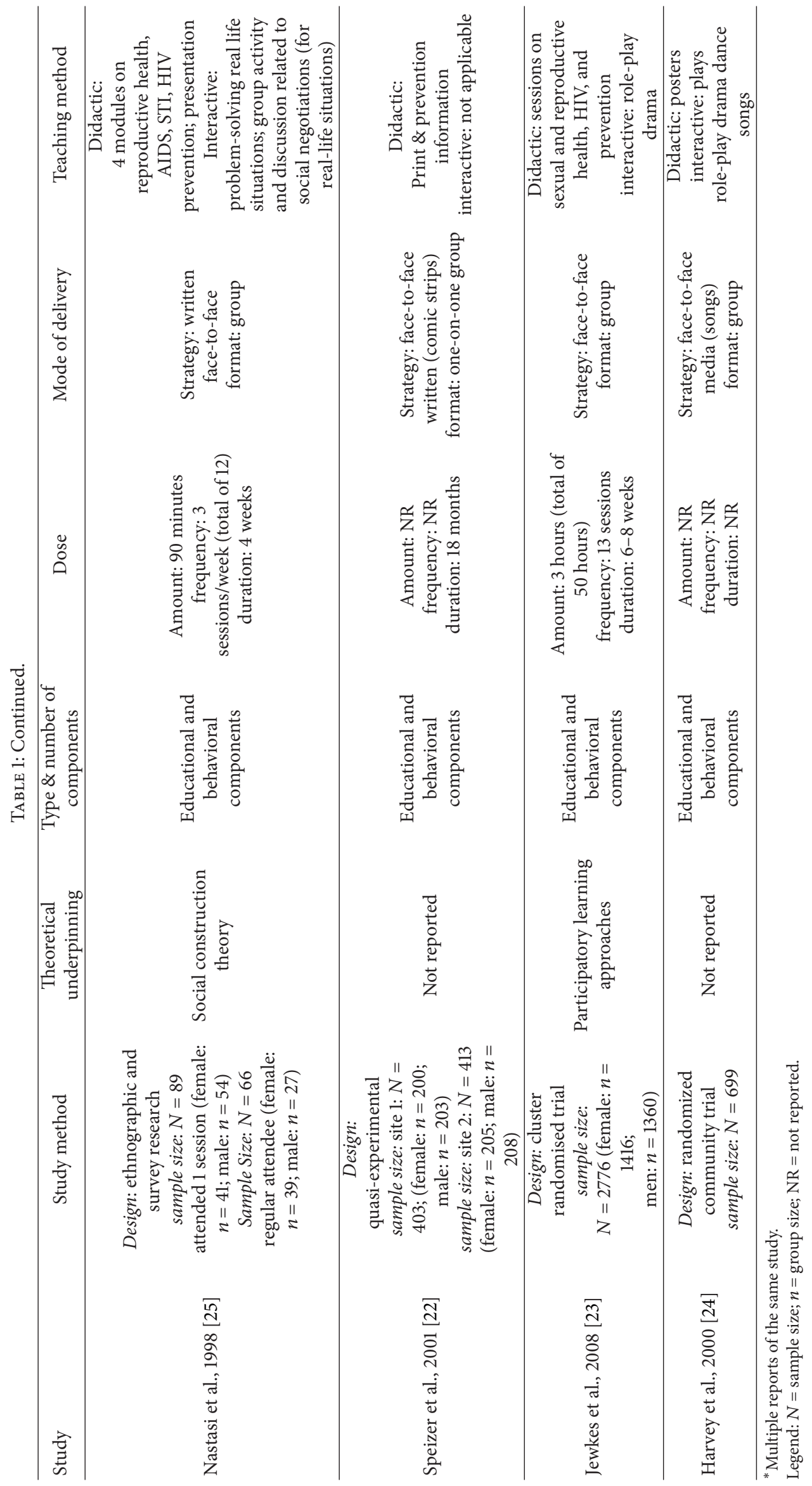


Health Organization's (WHO) knowledge, attitudes, beliefs, and practices measured both knowledge and self-reported risk behavior.

Of the eight studies evaluating the effects of the HIV prevention interventions on the outcome of knowledge, six $(75 \%)$ reported that the interventions were effective in improving knowledge $[12,17,20,22,24,25]$. Two studies found no statistically significant effects on knowledge [21, 29]. Seven (77\%) of the nine studies that evaluated the selfreported sexual risk behavior indicated that the interventions were effective in reducing this behavior [12, 18, 20-24]. One study (11\%) [17] showed statistically significant intervention effects on self-reported risk behavior in young males but not in young females. In contrast, one study [29] showed no statistically significant effect on this outcome.

\section{Influence of Intervention Characteristics on Outcome}

The ten publications included in the review addressed the outcome of knowledge and/or self-reported sexual risk behavior. Specifically, seven studies reported on both knowledge and self-reported risky behavior outcomes, two reported on self-reported risky behavior, and one reported on knowledge outcome.

4.1. Theoretical Underpinning. Of the five studies that used a theory to guide the design of the intervention, two reported significant effects on knowledge [12, 25, 29] and three found significant effect on self-reported risk behavior [12, 21, 23]. Of the remaining five studies that did not use a theory to guide the intervention, three reported statistically significant effects on knowledge and self-reported risk behavior [18, 22, 24]. Two studies [20,23] showed significant effect on self-reported risk behavior only and one study [17] revealed significant effects in knowledge and on self-reported risk behavior but only in young males and not young females.

4.2. Components. All studies evaluated multicomponent interventions. Four studies [12, 18, 22, 24] showed significant effect on knowledge and self-reported risk behavior. Three studies showed significant effects on self-reported risk behavior only $[20,21,23]$; and one on knowledge [25]. One study [17] found significant effects on knowledge and selfreported risk behavior only in young males. Similarly, one study [29] reported no significant effects of the intervention on knowledge and self-reported risk behavior (Table 2).

4.3. Dose. Of the five studies describing the amount and frequency of the intervention dose, one did not report significant effects on knowledge and self-reported risk behavior [29] and the remaining studies indicated statistically significant effects on self-reported risk behavior [20,23] and knowledge $[17,25]$. Ross et al. [17] reported significant effects on selfreported risk behaviour among young males but not young females. Of the five studies that did not describe the dose of the intervention, four $[12,18,22,24]$ reported statistically significant effects on knowledge and on self-reported risk behavior and one study [21] found significant effects on selfreported risk behavior. Seven studies described the duration of the intervention. Six studies $[12,17,20,22,23,25]$ reported significant effects on knowledge and self-reported risk behaviour, and one study [29] showed no statistically significant effects on knowledge and self-reported risk behavior. Of the remaining three studies that did not describe the duration of the intervention, two reported significant effects on knowledge and self-reported risk behavior $[18,24]$ and one study [21] on self-reported risk behavior.

4.4. Mode of Delivery. Of the six studies that applied a mixed mode of intervention delivery, four reported significant effects on knowledge [18, 22, 24, 25] and on self-reported risk behaviour [18, 21, 22, 24]. Ross et al., [17] reported statistical significant effects on knowledge and risk behavior only in young males. Of the four studies that applied face-to-face mode of delivery strategy, one [12] reported significant effects on knowledge and self-reported risk behavior; two on risk behavior [20, 23], and one study [29] showed no significant effects on knowledge and risk behavior (Table 2).

Of the four studies that used a mixed format for intervention delivery, two $[18,22]$ reported statistically significant effects on knowledge and self-reported risk behavior. One study [29] showed no significant effects on both outcomes and one [17] showed effectiveness in improving knowledge and self-reported risk behavior but only in young males. Of the five studies that used group format, two showed significant effects on both outcomes $[12,24]$, two studies $[20,23]$ on self-reported risk behavior only and one study on knowledge only [25] (Table 2).

4.5. Teaching Method. Of the nine studies that reported using mixed teaching method, four $[12,18,22,24]$ showed significant effects on knowledge and six on self-reported risk behavior [12, 13, 18, 20, 22, 23]. One study [25] found significant effects on knowledge and one study reported significant effects on both outcomes but only for young males [17]. However, one study [29] showed no significant effect on self-reported risk behavior and knowledge. The one study that used didactic teaching method showed significant effects on self-reported risk behavior [21].

\section{Discussion}

Community based HIV prevention interventions are an important resource for providing education to improve HIVrelated knowledge and for acquiring skills to decrease engagement in sexual risk behavior among young persons living in developing countries. This review focused on examining the characteristics of interventions that demonstrated effectiveness in achieving these outcomes. Knowledge of which intervention component delivered in what format and what dose is important to help researchers and healthcare providers design high quality, effective, and efficient interventions [13]. Effective interventions are ones that successfully address the presenting health problems and produce beneficial outcomes that are relevant to the target population [13]. For example, 
TABLE 2: Reported interventions' effects on knowledge and risk behavior outcome.

\begin{tabular}{|c|c|c|}
\hline Study & Knowledge & Risk behavior \\
\hline $\begin{array}{l}\text { Ross et al. } 2007 \text { [17]; Hayes } \\
\text { et al. } 2005[26]^{*} \text { and Doyle } \\
\text { et al., } 2010[27]^{*}\end{array}$ & $\begin{array}{l}\text { Statistically significant in the } \\
\text { hypothesized direction } \\
P<0.001\end{array}$ & $\begin{array}{l}\text { Statistically significant in the } \\
\text { hypothesized direction } \\
P<0.001 \\
{ }^{*} \text { Reported statistically significant effects } \\
\text { for young males, but not young females. }\end{array}$ \\
\hline Maro et al. 2009 [12] & $\begin{array}{l}\text { Statistically significant in the } \\
\text { hypothesized direction } \\
P<0.05\end{array}$ & $\begin{array}{l}\text { Statistically significant in the } \\
\text { hypothesized direction } \\
P<0.05\end{array}$ \\
\hline $\begin{array}{l}\text { Pettifor et al. } 2005[18] \text { and } \\
\text { Stadler and Hlongwa } 2002 \\
{[28]^{*}}\end{array}$ & Not applicable & $\begin{array}{l}\text { Statistically significant in the } \\
\text { hypothesized direction } \\
P<0.05\end{array}$ \\
\hline $\begin{array}{l}\text { Cowan et al. [29], 2008 and } \\
\text { Cowan et al. 2010* [19] }\end{array}$ & $\begin{array}{l}\text { Statistically nonsignificant in the } \\
\text { hypothesized direction } \\
P<0.001\end{array}$ & $\begin{array}{l}\text { Statistically nonsignificant in the } \\
\text { hypothesized direction } \\
P<0.001\end{array}$ \\
\hline Erulkar et al. 2004 [20] & $\begin{array}{l}\text { Statistically significant in the } \\
\text { hypothesized direction } \\
P<0.01\end{array}$ & $\begin{array}{l}\text { Statistically significant in the } \\
\text { hypothesized direction } \\
P<0.01\end{array}$ \\
\hline Underwood et al., 2006 [21] & $\begin{array}{l}\text { Statistically nonsignificant in the } \\
\text { hypothesized direction } \\
P<0.01\end{array}$ & $\begin{array}{l}\text { Statistically significant in the } \\
\text { hypothesized direction } \\
P<0.01\end{array}$ \\
\hline Nastasi et al., 1998 [25] & $\begin{array}{l}\text { Statistically significant in the } \\
\text { hypothesized direction } \\
P<0.01 \\
{ }^{*} \text { Reported improved knowledge for } \\
\text { young women }\end{array}$ & Not applicable \\
\hline Speizer et al., 2001 [22] & $\begin{array}{l}\text { Statistically significant in the } \\
\text { hypothesized direction } \\
P \leq 0.05\end{array}$ & $\begin{array}{l}\text { Statistically significant in the } \\
\text { hypothesized direction } \\
P<0.05\end{array}$ \\
\hline Jewkes et al., 2008 [23] & Not applicable & $\begin{array}{l}\text { Statistically significant in the } \\
\text { hypothesized direction } \\
P=0.063\end{array}$ \\
\hline Harvey et al., 2000 [24] & $\begin{array}{l}\text { Statistically significant in the } \\
\text { hypothesized direction } \\
P<0.01\end{array}$ & $\begin{array}{l}\text { Statistically significant in the } \\
\text { hypothesized direction } \\
P<0.01\end{array}$ \\
\hline
\end{tabular}

${ }^{*}$ Multiple reports of the same study.

community based HIV prevention interventions are considered effective if they enhance HIV-related knowledge, decrease engagement in self-reported risk behavior, and increase use of condoms to prevent the transmission of HIV. Efficient interventions are ones that produce the intended benefits at the minimum cost [13]. The cost may be financially related to the material and human resources needed to deliver the intervention or associated with participants' time and burden of attending the intervention sessions. Reducing participants' burden could enhance their attendance at the intervention sessions, engagement and adherence to the recommendations, and achievement of the beneficial outcomes [13]. Therefore, determining the contribution of the HIV-prevention interventions' characteristics has the potential to support researchers and healthcare providers in designing community based HIV prevention interventions in the most efficient and effective way that is attractive to young persons. In turn, attendance at these interventions enhances HIV-related knowledge and decreases engagement in risk behaviour and the transmission of HIV among young persons living in developing countries.

5.1. Theory. Findings of this review indicated inconsistent use of theory. This inconsistency has also been observed in studies of community based interventions conducted in developing countries [30]. Theories are essential in guiding the design of interventions $[13,31]$ and theory-based interventions are reported to be more effective than interventions that are not informed by theory $[32,33]$. Theories provide a clear understanding of the aspects of the problem that are amenable to change, direction in the identification of factors that may influence the effectiveness of the intervention, and elaboration of the process responsible for producing the hypothesized intervention effects on the outcomes [34, 35]. Accordingly, the theory-informed intervention is carefully designed to target the problem and to induce changes in the mediating variables and subsequently the ultimate outcomes [36]. Although the literature highlights the benefits of 
utilizing a theory to guide the design and implementation of an intervention, findings from this review show interventions were effective regardless of whether or not they were guided by a theory.

5.2. Components. All studies investigated multicomponent interventions and the majority reported significant improvement in HIV-related knowledge and reduction in selfreported engagement in sexual risk behavior among young persons. The interventions consisted of an educational component that covered information on reproductive and sexual health and general information on HIV and its prevention and a behavioral component that addressed the adoption of safer sexual practices (e.g., sexual negotiation skills, reduction of number of sexual partners, use of condoms). Findings from this review are consistent with empirical evidence showing that multicomponent interventions are more effective than single-component interventions in the promotion of physical activity [31], management of Warfarin therapy [37], delirium [38], symptoms in persons living with HIV [39], and diabetes [40]. Educational components alone, although useful in raising awareness and improving knowledge, are insufficient and inadequate in altering risk behavior and motivating application of health behavior [41-44]. The behavioral component complements the educational component because it focuses not only on knowledge acquisition but also on behavior performance [45]. Hence, incorporating multiple components has the potential to create a synergistic effect [46, page 62] in improving young persons' application of information and skills learned into their daily life.

5.3. Dose. The description of the intervention dose in the reviewed studies was vague and only a few studies reported on the amount, frequency, and duration for delivering the intervention. Findings from this review identified insufficient specification of the intervention dose and inconsistency in its overall contribution to the outcomes. The insufficient information on intervention dose limits the ability to draw conclusions on how much of the community based HIVprevention intervention is needed to achieve the desired effects [47]. In addition, the justification for the intervention dose was not provided, raising concerns regarding the adequacy as well as the fidelity of the treatment delivered to participants [31]. Evidence suggests that in general HIV prevention interventions tend to be delivered in a high number of sessions and given over a long period of time; this high intervention dose was associated with the achievement of the expected outcomes [39, 48-53]. Multiple sessions reinforce information gained and provide young persons with opportunity to clarify and acquire the knowledge and to practice the skills required for engagement in health sexual behaviors.

5.4. Mode of Delivery. Different modes were described for the intervention implementation in the reviewed studies. The most frequent mode was face-to-face contact in a group format, combination of written material, video, and face-to-face interaction. Findings were similar to those of a meta-analysis on self-management of diabetes [40], and HIV prevention interventions for persons living with $\operatorname{HIV}[39,51,52,54]$ and not living with HIV $[48,49,55-58]$. Utilizing different modes to deliver community based HIV prevention interventions provides learning opportunities for young persons that may be consistent with different learning styles, preferences, and needs.

5.5. Teaching Method. The majority of studies reported using a mixed teaching method, which included both didactic (e.g., printed material) and interactive methods (e.g., drama, story-telling, soccer, role-play) for providing the HIV prevention interventions. Most interventions were effective, despite variability in teaching method. A mixed teaching method promotes learning because the various educational strategies meet the different learning styles and preferences of young people [59]. By including mixed teaching methods, the interventions would be appealing to young men and women and would allow them to be active in the learning process and, in turn, increase the uptake of the information provided [59].

\section{Limitations}

The number of studies included in this systematic review was small and findings showed variability in the design of community based HIV prevention interventions. The small number and high variability limited the ability to compare and contrast the influence of the intervention characteristics on the outcomes and, in turn, determine the most effective characteristics in designing and developing efficient and effective interventions.

\section{Implications}

Overall, the results indicated that most HIV prevention interventions are effective in enhancing knowledge and reducing self-reported risk behaviour in young persons residing in developing countries; however, the intervention characteristics did contribute significantly to the interventions' effectiveness. However, the findings reinforce the importance of carefully designing community based HIV prevention interventions in a way that would improve their effectiveness and efficiency. Such an intervention can be designed to include (1) multiple (educational and behavioral) components, as they have a synergist or complementary effect on improving knowledge and reducing engagement in sexual risk behavior among young persons; (2) mixed mode of delivery, including group format, video, and face-to-face interaction; and (3) mixed teaching methods, including didactic (i.e., written material) and interactive (i.e., sports and drama) methods. The limited information on intervention dose highlights the importance of thoroughly describing the amount, frequency, and duration of the intervention delivery in order to identify the dose that is most effective in producing the hypothesized outcomes, yet feasible within the constraint of the community practice setting. Findings from this review further highlight the importance of using mixed teaching method and mode of delivery of community based HIV prevention interventions 
to address the different learning preferences and needs of young persons living in developing countries.

\section{Conclusion}

Result of this systematic review provides direction for developing and implementing community based HIV prevention interventions that are effective in increasing HIV-related knowledge and decreasing self-report of engagement in sexual risk behavior among young persons living in developing countries. Findings from this review support using multicomponent (educational and behavioral), mixed mode of delivery, and teaching method. As a result of the continued burden and impact of the HIV/AIDS epidemic, sustained focus on developing and evaluating community based HIV prevention interventions, specifically the characteristics of the interventions, is imperative to improve HIV-related knowledge and decrease engagement in risk behavior for young persons living in developing countries.

\section{Disclosure}

This is to confirm all authors have reviewed the submitted paper and approved the paper for submission.

\section{Conflict of Interests}

No conflict of interests declared. This paper has not been published elsewhere and is not under submission elsewhere.

\section{References}

[1] World Health Organization (WHO), "HIV \& AIDS," 2010, http://www.who.int/features/qa/71/en/index.html.

[2] UNAIDS, 2009, http://data.unaids.org/pub/FactSheet/2009/ 20091124_FS_global_en.pdf.

[3] World Health Organization (WHO), Immunization, Vaccinesand Biologicals: HIV\&AIDS, World Health Organization (WHO), Geneva, Switzerland, 2007, http://www.who.int/ immunization/topics/hiv/en/indexl.html.

[4] UNAIDS, "Global Report on the Global AIDS Epidemic," 2010, http://www.unaids.org/documents/20101123_GlobalReport_em .pdf.

[5] Ministry of Health [VietNam], HIV/AIDS estimates and projections 2005-2010, General Department of Preventive Medicine and HIV/AIDS Control, Ministry of Health, Hanoi, Vietnam, 2010.

[6] UNAIDS, "Young men and HIV: Culture, Poverty and Sexual Risk," 2001, http://data.unaids.org/publications/IRC-pub04/ youngmenandhiv_en.pdf.

[7] G. R. Gupta, "How men's power over women fuels the HIV epidemic," The British Medical Journal, vol. 324, no. 7331, pp. 183-185, 2002.

[8] T. Türmen, "Gender \& HIV/AIDS," International Journal of Gynecology and Obstetrics, vol. 82, no. 3, pp. 411-418, 2003.

[9] T. J. Coates, L. Richter, and C. Caceres, "Behavioural strategies to reduce HIV transmission: how to make them work better," The Lancet, vol. 372, no. 9639, pp. 669-684, 2008.
[10] United Nations (n.d.), "HIV/AIDS," http://www.un.org/works/ sub2.asp?lang=en\&s=34.

[11] UNAIDS, "Global Report. UNAIDS report on the Gloabl AIDS epidemic 2013," 2013, http://www.unaids.org/en/media/ unaids/contentassets/documents/epidemiology/2013/gr2013/ unaids_global_report_2013_en.pdf.

[12] C. N. Maro, G. C. Roberts, and M. Sørensen, "Using sport to promote HIV/AIDS education for at-risk youths: an intervention using peer coaches in football," Scandinavian Journal of Medicine and Science in Sports, vol. 19, no. 1, pp. 129-141, 2009.

[13] S. Sidani and C. J. Braden, Design, Evaluation, and Translation of Nursing Interventions, Wiley-Blackwell, Ames, Iowa, USA, 2011.

[14] B. K. Odu and F. F. Akanle, "Knowledge of HIV/AIDS and sexual behaviour among the youths in South West Nigeria," Humanity and Social Sciences Journal, vol. 3, no. 1, pp. 81-88, 2008.

[15] World Health Organization (WHO), Global Health Sector Strategy on HIV/AIDS 2011-2015, 2011, http://whqlibdoc.who .int/publications/2011/9789241501651_eng.pdf.

[16] N. Maimaiti, K. Shamsuddin, A. Abdurahim, N. Tohti, and R. Memet, "Knowledge, attitude, practice regarding HIV/AIDS among university students in Xinjiang," Global Journal of Health Science, vol. 2, no. 2, pp. 51-60, 2010.

[17] D. A. Ross, J. Changalucha, A. I. N. Obasi et al., "Biological and behavioural impact of an adolescent sexual health intervention in Tanzania: a community-randomized trial," AIDS, vol. 21, no. 14, pp. 1943-1955, 2007.

[18] A. E. Pettifor, I. Kleinschmidt, J. Levin et al., "A communitybased study to examine the effect of a youth HIV prevention intervention on young people aged 15-24 in South Africa: results of the baseline survey," Tropical Medicine and International Health, vol. 10, no. 10, pp. 971-980, 2005.

[19] F. M. Cowan, S. J. S. Pascoe, L. F. Langhaug et al., "The Regai Dzive Shiri project: results of a randomized trial of an HIV prevention intervention for youth," AIDS, vol. 24, no. 16, pp. 2541-2552, 2010

[20] A. S. Erulkar, L. I. A. Ettyang, C. Onoka, F. K. Nyagah, and A. Muyonga, "Behavior change evaluation of a culturally consistent reproductive health program for young Kenyans," International Family Planning Perspectives, vol. 30, no. 2, pp. 5867, 2004.

[21] C. Underwood, H. Hachonda, E. Serlemitsos, and U. BharathKumar, "Reducing the risk of HIV transmission among adolescents in Zambia: psychosocial and behavioral correlates of viewing a risk-reduction media campaign," Journal of Adolescent Health, vol. 38, no. 1, pp. 55.el-55.e13, 2006.

[22] I. S. Speizer, B. O. Tambashe, and S.-P. Tegang, "An evaluation of the "Entre Nous Jeunes" Peer-educator program for adolescents in Cameroon," Studies in Family Planning, vol. 32, no. 4, pp. 339-351, 2001.

[23] R. Jewkes, M. Nduna, J. Levin et al., "Impact of stepping stones on incidence of HIV and HSV-2 and sexual behaviour in rural South Africa: cluster randomised controlled trial," British Medical Journal, vol. 337, no. 7, pp. 506-517, 2008.

[24] B. Harvey, J. Stuart, and T. Swan, "Evaluation of a drama-ineducation programme to increase AIDS awareness in South African high schools: a randomized community intervention trial," International Journal of STD and AIDS, vol. 11, no. 2, pp. 105-111, 2000.

[25] B. K. Nastasi, J. J. Schensul, and M. W. de Silva, "Communitybased sexual risk prevention program for Sri Lankan youth: 
Influencing sexual risk decision making," International Quarterly of Community Health Education, vol. 18, pp. 139-155, 1998.

[26] R. J. Hayes, J. Changalucha, D. A. Ross et al., "The MEMA kwa Vijana Project: design of a community randomised trial of an innovative adolescent sexual health intervention in rural Tanzania," Contemporary Clinical Trials, vol. 26, no. 4, pp. 430442, 2005.

[27] A. M. Doyle, D. A. Ross, K. Maganja et al., "Long-term biological and behavioural impact of an adolescent sexual health intervention in tanzania: Follow-up survey of the communitybased mema kwa vijana trial," PLoS Medicine, vol. 7, no. 6, Article ID e1000287, 2010.

[28] J. Stadler and L. Hlongwa, "Monitoring and evaluation of loveLife's AIDS prevention and advocacy activities in South Africa, 1999-2001," Evaluation and Program Planning, vol. 25, no. 4, pp. 365-376, 2002.

[29] F. M. Cowan, S. J. S. Pascoe, L. F. Langhaug et al., "The Regai Dzive Shiri Project: a cluster randomised controlled trial to determine the effectiveness of a multi-component community-based HIV prevention intervention for rural youth in Zimbabwe-study design and baseline results," Tropical Medicine \& International Health, vol. 13, no. 10, pp. 1235-1244, 2008.

[30] E. Maticka-Tyndale and C. Brouillard-Coyle, "The effectiveness of community interventions targeting HIV and AIDS prevention at young people in developing countries," World Health Organization, no. 938, pp. 243-285, 2006.

[31] C. L. Blue and D. R. Black, "Synthesis of intervention research to modify physical activity and dietary behaviors," Research and Theory for Nursing Practice, vol. 19, no. 1, pp. 25-61, 2005.

[32] J. E. Painter, C. P. C. Borba, M. Hynes, D. Mays, and K. Glanz, "The use of theory in health behavior research from 2000 to 2005: a systematic review," Annals of Behavioral Medicine, vol. 35, no. 3, pp. 358-362, 2008.

[33] S. M. Noar and R. S. Zimmerman, "Health behavior theory and cumulative knowledge regarding health behaviors: are we moving in the right direction?" Health Education Research, vol. 20, no. 3, pp. 275-290, 2005.

[34] M. Fishbein, "The role of theory in HIV prevention," AIDS Care, vol. 12, no. 3, pp. 273-278, 2000.

[35] K. S. McGilton, V. Boscart, M. Fox, S. Sidani, E. Rochon, and R. Sorin-Peters, "A systematic review of the effectiveness of communication interventions for health care providers caring for patients in residential care settings," Worldviews on EvidenceBased Nursing, vol. 6, no. 3, pp. 149-159, 2009.

[36] R. Foy, J. J. Francis, M. Johnston et al., "The development of a theory-based intervention to promote appropriate disclosure of a diagnosis of dementia," BMC Health Services Research, vol. 7, article 207, pp. 202-215, 2007.

[37] R. J. Beyth, L. Quinn, and C. S. Landefeld, "A multicomponent intervention to prevent major bleeding complications in older patients receiving warfarin: a randomized, controlled trial," Annals of Internal Medicine, vol. 133, no. 9, pp. 687-695, 2000.

[38] K. Milisen, J. Lemiengre, T. Braes, and M. D. Foreman, "Multicomponent intervention strategies for managing delirium in hospitalized older people: systematic review," Journal of Advanced Nursing, vol. 52, no. 1, pp. 79-90, 2005.

[39] N. Crepaz, C. M. Lyles, R. J. Wolitski et al., "Do prevention interventions reduce HIV risk behaviours among people living with HIV? A meta-analytic review of controlled trials," AIDS, vol. 20, no. 2, pp. 143-157, 2006.
[40] L. Fan and S. Sidani, "Effectiveness of diabetes self-management education intervention elements: a meta-analysis," Canadian Journal of Diabetes, vol. 33, no. 1, pp. 18-26, 2009.

[41] R. S. Gold, M. J. Skinner, and M. W. Ross, "Unprotected anal intercourse in HIV-infected and non-HIV-infected gay men," Journal of Sex Research, vol. 31, no. 1, pp. 59-77, 1994.

[42] T. P. Jagdeo, "Social structure, reproductive health and the knowledge-behaviour gap," Promotion \& Education, vol. 3, no. 3, pp. 11-14, 1996.

[43] J. Shepherd, G. Peersman, R. Weston, and I. Napuli, "Cervical cancer and sexual lifestyle: a systematic review of health education interventions targeted at women," Health Education Research, vol. 15, no. 6, pp. 681-694, 2000.

[44] N. Shipley, Stage of readiness and learning styles- a tailored HIV/AIDS prevention intervention for youth detained in the Los Angeles county juvenile justice system [M.S. thesis], 2008.

[45] L. M. Coleman and N. J. Ford, "An extensive literature review of the evaluation of HIV prevention programmes," Health Education Research, vol. 11, no. 3, pp. 327-338, 1996.

[46] L. Brown, K. Macintyre, and L. Trujillo, "Interventions to reduce HIV/AIDS stigma: what have we learned?" AIDS Education and Prevention, vol. 15, no. 1, pp. 49-69, 2003.

[47] D. Doran, M. B. Harrison, H. Laschinger et al., "Relationship between nursing interventions and outcome achievement in acute care settings," Research in Nursing and Health, vol. 29, no. 1, pp. 61-70, 2006.

[48] M. Gallant and E. Maticka-Tyndale, "School-based HIV prevention programmes for African youth," Social Science \& Medicine, vol. 58, no. 7, pp. 1337-1351, 2004.

[49] K.-I. Klepp, S. S. Ndeki, M. T. Leshabari, P. J. Hannan, and B. A. Lyimo, "AIDS education in Tanzania: promoting risk reduction among primary school children," American Journal of Public Health, vol. 87, no. 12, pp. 1931-1936, 1997.

[50] A. Margolin, S. K. Avants, L. A. Warburton, K. A. Hawkins, and J. Shi, "A randomized clinical trial of a manual-guided risk reduction intervention for HIV-positive injection drug users," Health Psychology, vol. 22, no. 2, pp. 223-228, 2003.

[51] M. J. Rotheram-Borus, Z. O'Keefe, R. Kracker, and H.-H. Foo, "Prevention of HIV among adolescents," Prevention Science, vol. 1, no. 1, pp. 15-30, 2000.

[52] G. M. Wingood, R. J. DiClemente, I. Mikhail et al., "A randomized controlled trial to reduce HIV transmission risk behaviors and sexually transmitted diseases among women living with HIV: the WiLLOW Program," Journal of Acquired Immune Deficiency Syndromes, vol. 37, pp. S58-S67, 2004.

[53] R. J. Wolitski, C. A. Gómez, and J. T. Parsons, "Effects of a peerled behavioral intervention to reduce HIV transmission and promote serostatus disclosure among HIV-seropositive gay and bisexual men," AIDS, vol. 19, no. 1, pp. S99-S109, 2005.

[54] T. L. Patterson, W. S. Shaw, and S. J. Semple, "Reducing the sexual risk behaviors of HIV+ individuals: outcome of a randomized controlled trial," Annals of Behavioral Medicine, vol. 25, no. 2, pp. 137-145, 2003.

[55] A. M. Fitzgerald, B. F. Stanton, N. Terreri et al., "Use of westernbased HIV risk-reduction interventions targeting adolescents in an african setting," Journal of Adolescent Health, vol. 25, no. 1, pp. 52-61, 1999.

[56] J. Kinsman, J. Nakiyingi, A. Kamali et al., "Evaluation of a comprehensive school-based aids education programme in rural Masaka, Uganda," Health Education Research, vol. 16, no. 1, pp. 85-100, 2001. 
[57] L. Kuhn, M. Sternberg, and C. Mathews, "Participation of the school community in AIDS education: an evaluation of a high school programme in South Africa," AIDS Care, vol. 6, no. 2, pp. 161-171, 1994.

[58] D. A. Shuey, B. B. Babishangire, S. Omiat, and H. Bagarukayo, "Increased sexual abstinence among in-school adolescents as a result of school health education in Soroti district, Uganda," Health Education Research, vol. 14, no. 3, pp. 411-419, 1999.

[59] K. E. Ito, S. Kalyanaraman, C. A. Ford, J. D. Brown, and W. C. Miller, "'Let's talk about sex": pilot study of an interactive CD-ROM to prevent HIV/STIs in female adolescents," AIDS Education and Prevention, vol. 20, no. 1, pp. 78-89, 2008. 


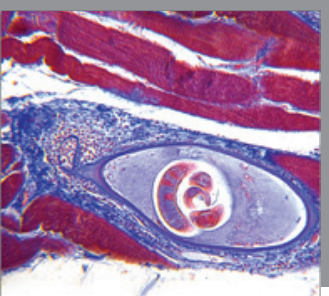

Gastroenterology

Research and Practice
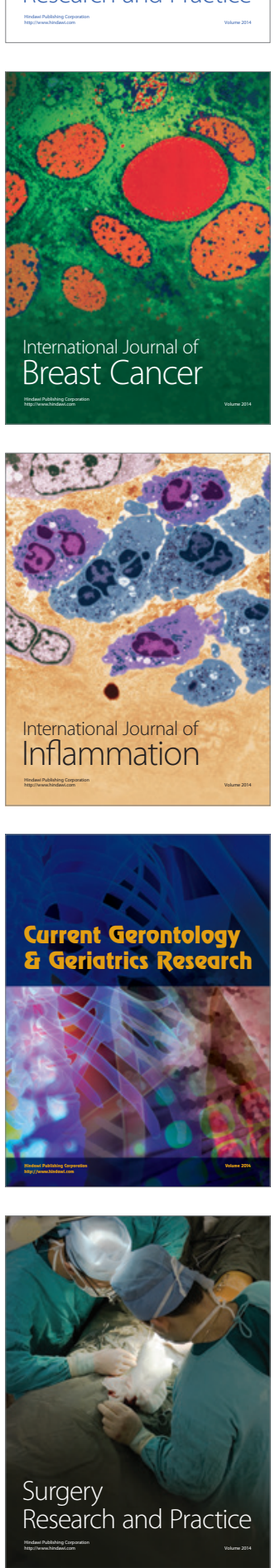

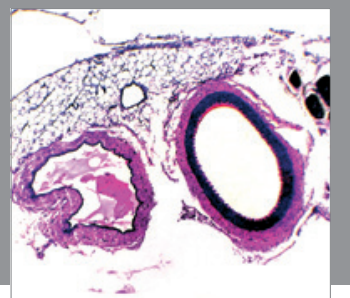

International Journal of Hypertension
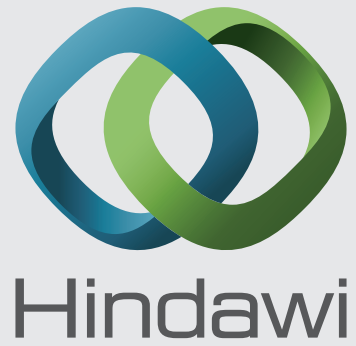

Submit your manuscripts at http://www.hindawi.com
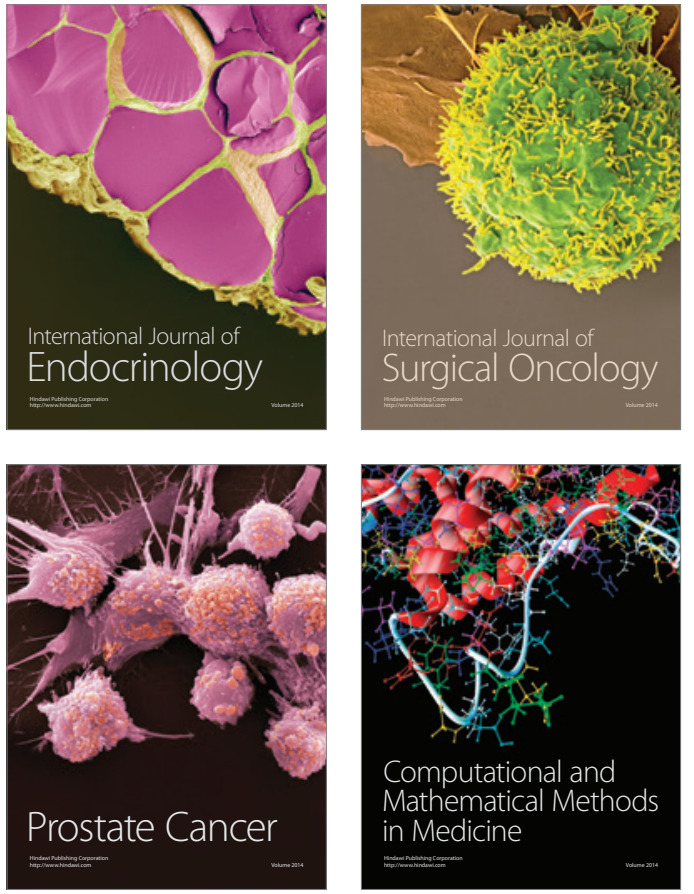
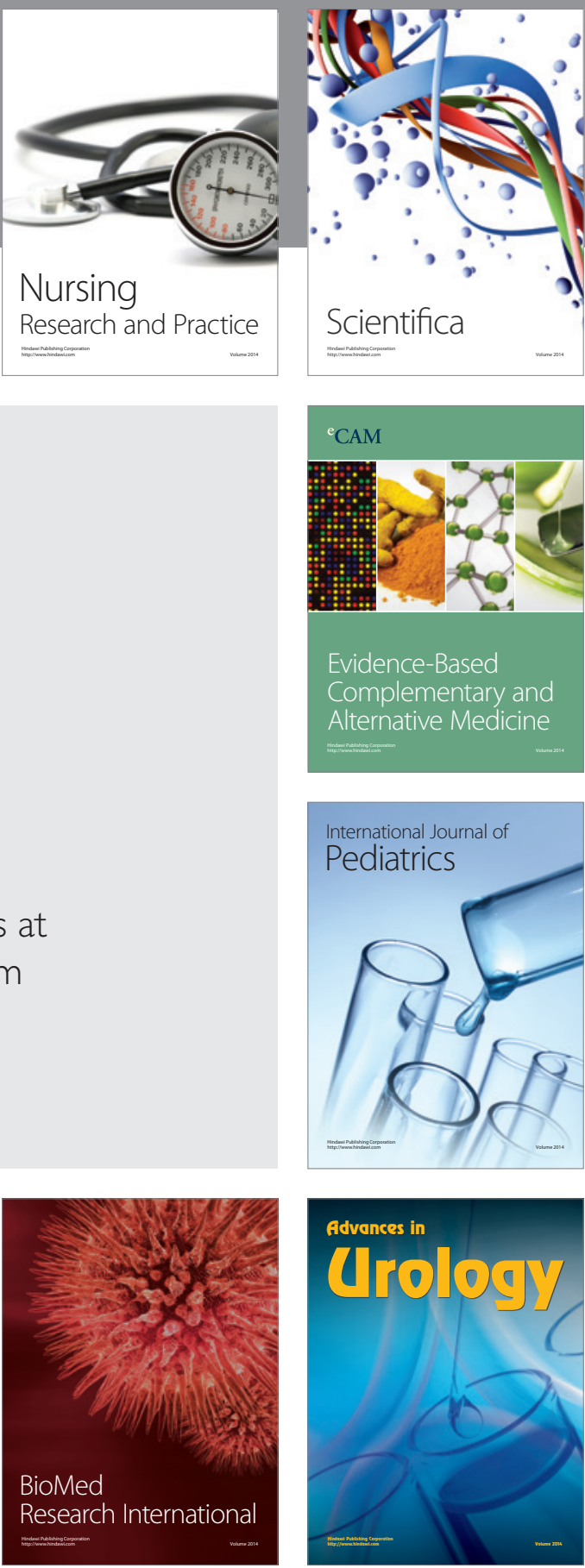

Nursing

Research and Practice

Scientifica

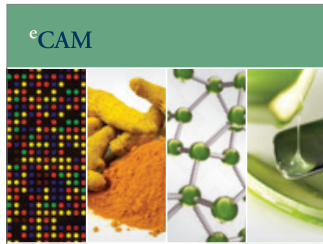

Evidence-Based

Complementary and Alternative Medicine
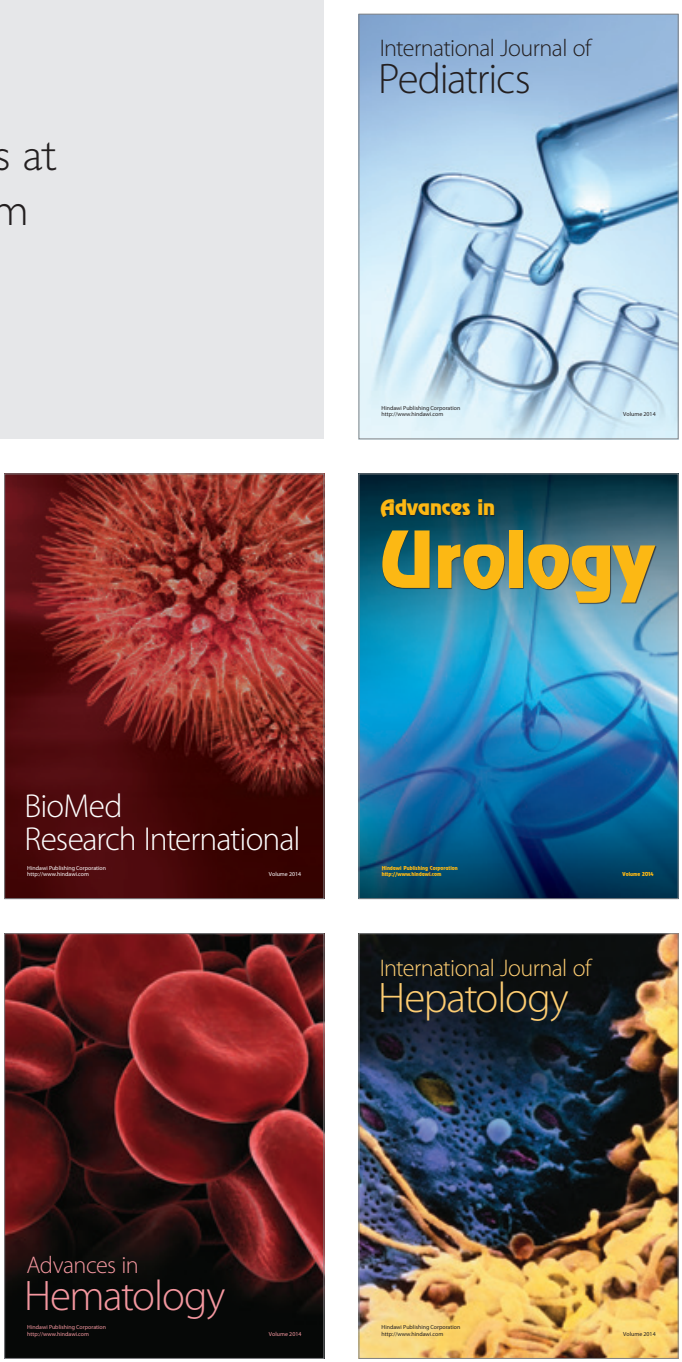